\title{
The impact of time to thrombolytic treatment on outcome in patients with acute myocardial infarction
}

\author{
P Chareonthaitawee, R J Gibbons, R S Roberts, T F Christian, R Burns, S Yusuf, for the \\ CORE investigators
}

\begin{abstract}
Objectives-To examine the impact of time to thrombolytic treatment on multiple acute outcome variables in a single trial of thrombolysis in acute myocardial infarction.

Design and patients-Mortality and reinfarction rate were measured in 2770 patients with acute myocardial infarction who received thrombolysis within 12 hours in CORE, an international, dose ranging trial of poloxamer 188 . Tc-99m sestamibi infarct size and radionuclide angiographic ejection fraction substudies included 1099 and 1074 patients, respectively.

Results-Time to thrombolysis, subgrouped by intervals $(<2,2-4, \geqslant 4-6$, and $\geqslant 6$ hours), was significantly associated with infarct size (median $15.0 \%, 18.5 \%, 22.0 \%, 18.5 \%$ of left ventricle; $\mathrm{p}=0.033)$, mean (SD) ejection fraction (51.5 (12.0)\%, $48.3(13.9) \%, 48.2$ (13.3)\%, 48.2 $(15.0) \% ; \mathrm{p}=0.006)$, 35 day mortality $(5.7 \%, 7.1 \%, 7.9 \%, 12.5 \% ; \mathrm{p}=0.0004)$, six month mortality $(7.3 \%, 8.6 \%, 10.4 \%, 15.5 \% ; \mathrm{p}<0.0001)$, and 35 day reinfarction rate $(6.1 \%, 3.2 \%, 4.0 \%$, $0.9 \% ; \mathrm{p}=0.0001)$.

Conclusions-In this single large trial, the beneficial effect of time to thrombolysis on infarct size and ejection fraction was restricted to treatment given within two hours of symptom onset, while the effect on mortality was evident over all time intervals. Reinfarction rate was higher in patients treated with earlier thrombolysis.

(Heart 2000;84:142-148)
\end{abstract}

Keywords: myocardial infarction; thrombolysis; infarct size

\section{Division of \\ Cardiovascular \\ Diseases and Internal \\ Medicine, Mayo Clinic \\ and Foundation, \\ Rochester, Minnesota, \\ USA \\ P Chareonthaitawee \\ R J Gibbons \\ T F Christian}

Hamilton Civic

Hospital Research

Centre, Hamilton,

Ontario, Canada

R S Roberts

Nuclear Cardiology

Laboratory, The

Toronto Hospital,

Toronto, Ontario,

Canada

R Burns

Hamilton General

Hospital-McMaster

Clinic, Hamilton,

Ontario, Canada

$S$ Yusuf

Correspondence to: Dr P Chareonthaitawee, MRC Cyclotron Unit, Imperial College School of Medicine, Hammersmith Hospital, Du Cane Road, London W12 ONN, UK. email:

panithaya.chareonthaitawee@ csc.mrc.ac.uk

Accepted 29 February 2000
The benefits of thrombolytic treatment are greatest when it is given early in acute myocardial infarction. ${ }^{1}$ In animal models, infarct size and left ventricular function, the major prognostic determinants in clinical myocardial infarction, were adversely affected in a rapid and non-linear fashion by the duration of coronary occlusion..$^{23}$ Attempts to demonstrate such an association in clinical studies have yielded conflicting results. One meta-analysis ${ }^{1}$ and two trials ${ }^{4}$ of thrombolysis in acute myocardial infarction suggest a direct linear effect of time to thrombolysis on mortality, infarct size, and ejection fraction, with a gradual diminution of benefit with increasing delay. In contrast, other clinical trials ${ }^{6-8}$ indicate a non-linear delay/benefit relation, with a pronounced decline in benefit after occlusion of one to three hours. Beyond this time threshold, other factors - such as the degree of myocardium at risk, collateral blood flow, and metabolic demand-exert a greater impact on outcome..$^{10}$

Reports on the effect of time to thrombolysis in acute myocardial infarction are restricted to selected outcome measures and smaller trials. ${ }^{15} 7811-16$ Most of these studies have analysed only short term mortality. Our aim in the present study was therefore to examine the association between time to administration of thrombolytic treatment and multiple end points-infarct size, ejection fraction, 35 day and six month mortality, and 35 day reinfarction rate-in a single trial of thrombolysis in acute myocardial infarction. Although there is evidence of benefit from thrombolysis beyond six hours to within 12 hours from symptom onset, ${ }^{17}$ time increments beyond six hours were not analysed in this study owing to the smaller benefits relative to earlier reperfusion treatment. ${ }^{18}$

\section{Methods}

The Collaborative Organisation for RheothRx Evaluation (CORE) trial was an international, multicentre, randomised, dose ranging study of poloxamer 188 (RheothRx; Burroughs Wellcome, USA) in acute myocardial infarction. ${ }^{14}$

\section{STUDY POPULATION}

In all, 2948 patients were randomised. Patients were eligible if they had symptoms consistent with acute myocardial infarction and at least $1 \mathrm{~mm}$ ST segment elevation in two or more contiguous ECG leads or new left bundle branch block. Exclusion criteria have been reported previously. ${ }^{14}$

Thrombolytic treatment was strongly encouraged; the 144 patients $(4.9 \%)$ who did not receive thrombolysis were excluded, as were 28 $(0.9 \%)$ with missing time to thrombolysis. Choice of the thrombolytic agent and other standard treatments was at the discretion of the attending physician. Patients were randomised in a blinded fashion to either thrombolysis alone, or to thrombolytic treatment plus one of five dosing regimens of poloxamer 188. The overall effect of this agent on mortality, ejection fraction, and infarct size was not significant. ${ }^{14}$ 
Table 1 Clinical characteristics of SPECT versus non-SPECT patients

\begin{tabular}{|c|c|c|c|c|c|c|}
\hline & $\begin{array}{l}\text { SPECT } \\
(n=1099)\end{array}$ & $\begin{array}{l}\text { Non-SPECT } \\
(n=656)\end{array}$ & $p$ Value & $\begin{array}{l}\text { SPECT } \\
(n=1099)\end{array}$ & $\begin{array}{l}\text { Non-SPECTt } \\
(n=1673)\end{array}$ & $p$ Value \\
\hline Age (years) & $58(11)$ & $60(12)$ & $<0.001$ & $58(11)$ & $60(11)$ & $<0.001$ \\
\hline Male sex & $79 \%$ & $73 \%$ & 0.006 & $79 \%$ & $76 \%$ & 0.068 \\
\hline \multicolumn{7}{|l|}{ History } \\
\hline Angina & $34 \%$ & $43 \%$ & $<0.001$ & $34 \%$ & $41 \%$ & $<0.001$ \\
\hline Previous MI & $15 \%$ & $21 \%$ & 0.002 & $15 \%$ & $18 \%$ & 0.029 \\
\hline PTCA or CABG & $8 \%$ & $9 \%$ & 0.48 & $8 \%$ & $7 \%$ & 0.29 \\
\hline Hypertension & $42 \%$ & $48 \%$ & 0.007 & $42 \%$ & $44 \%$ & 0.29 \\
\hline Diabetes & $15 \%$ & $19 \%$ & 0.059 & $15 \%$ & $16 \%$ & 0.88 \\
\hline Never smoked & $31 \%$ & $35 \%$ & 0.12 & $31 \%$ & $33 \%$ & 0.037 \\
\hline Anterior infarct & $40 \%$ & $45 \%$ & 0.084 & $40 \%$ & $44 \%$ & 0.062 \\
\hline \multicolumn{7}{|l|}{ Type of thrombolysis } \\
\hline $\mathrm{t}-\mathrm{PA}$ & $28 \%$ & $20 \%$ & $<0.001$ & $28 \%$ & $24 \%$ & 0.017 \\
\hline Streptokinase & $72 \%$ & $79 \%$ & & $72 \%$ & $75 \%$ & \\
\hline Other & $0 \%$ & $0 \%$ & & $0 \%$ & $1 \%$ & \\
\hline $\begin{array}{c}\beta \text { Blockers before } \\
\text { randomisation }\end{array}$ & $22 \%$ & $22 \%$ & 0.79 & $22 \%$ & $21 \%$ & 0.49 \\
\hline \multicolumn{7}{|l|}{ At presentation: } \\
\hline Heart rate (beats/min) & $77(17)$ & $78(17)$ & 0.073 & $77(17)$ & $78(18)$ & 0.17 \\
\hline Diastolic BP (mm Hg) & $82(16)$ & $82(16)$ & 0.90 & $82(16)$ & $81(15)$ & 0.05 \\
\hline Systolic BP (mm Hg) & $132(24)$ & $131(25)$ & 0.11 & $132(24)$ & $132(25)$ & 0.71 \\
\hline $\mathrm{HR} \times$ diastolic $\mathrm{BP}$ & $6340(2152)$ & $6455(2126)$ & 0.27 & $6340(2152)$ & $6311(2100)$ & 0.73 \\
\hline $\mathrm{HR} \times$ systolic $\mathrm{BP}$ & 10258 (3397) & $10292(3335)$ & 0.84 & $10258(3397)$ & 10319 (3389) & 0.64 \\
\hline
\end{tabular}

Data are expressed as mean (SD) or as percentage of patients.

^In SPECT centres; tin all centres.

$\mathrm{BP}$, blood pressure; CABG, coronary artery bypass graft; HR, heart rate; MI, myocardial infarction; PTCA, percutaneous transluminal coronary angioplasty; SPECT, single photon emission computed tomography; t-PA, tissue plasminogen activator.

HISTORICAL AND HAEMODYNAMIC VARIABLES Multiple clinical variables were recorded prospectively for each patient (table 1). Follow up was obtained at 35 days and six months.

CLINICAL OUTCOME EVENTS

Patients were monitored for outcome (death, reinfarction, or cardiogenic shock) while in hospital with the qualifying acute myocardial infarct, and after discharge, at 35 days and six months. During the index hospital admission, cardiogenic shock was diagnosed if the patient had, first, a persistently low systolic blood pressure $(<90 \mathrm{~mm} \mathrm{Hg}$ ) which was not responsive to fluid therapy alone, required intravenous inotropic support, and was felt to reflect cardiac dysfunction; and second, clinical evidence of poor perfusion (for example, decreased skin temperature, cyanosis, reduced urine output). After the index hospital admission, cardiogenic shock was recorded if the patient was readmitted and required intravenous inotropic support, and if there was a discharge diagnosis of cardiogenic shock. In unusual situations, inotropic support included management with mechanical support (for example, pump or ventilation), without initial intravenous inotropes.

TC-99m SESTAMIBI INFARCT SIZE SUBSTUDY The Tc-99m sestamibi infarct size SPECT (single photon emission computed tomography) substudy included 104 centres and a central laboratory at the Mayo Clinic in Minnesota, USA. If participating in the infarct size substudy, the centre was expected to enrol all eligible patients. Before infarct size assessment, cumulative mortality for the infarct size substudy group was $5.3 \%$ at day 6 and $6.3 \%$ at day 16 , and the revascularisation rate was $13.8 \%$ (152 patients), with a mortality of 3.3\% (five patients). Infarct size assessment was subsequently performed on 1113 patients between day 6 and day 16 . Fourteen patients (1.2\%) were excluded for technical reasons. In all, 1099 patients were analysed. Quality control of all imaging cameras was performed before patient studies. ${ }^{15}{ }^{16}$ Tc-99m sestamibi acquisition was carried out as previously described ${ }^{16}$ and validated in animal ${ }^{19}$ and clinical studies, ${ }^{20}$ where a $60 \%$ threshold has been shown to provide optimal separation between viable and non-viable myocardium. ${ }^{21}$ The raw planar image data were forwarded to the central core laboratory for infarct size quantitation (expressed as per cent of left ventricle). This measurement included new and old infarcts.

\section{RADIONUCLIDE ANGIOGRAPHY OF LEFT}

VENTRICULAR FUNCTION

The radionuclide angiography (RNA) substudy included 114 centres and a central laboratory at The Toronto Hospital, Ontario, Canada. If participating in the RNA substudy, the centre was expected to enrol all eligible patients. Before RNA assessment, cumulative mortality was $4.9 \%$ at day 6 and $6.2 \%$ at day 16 , and revascularisation rate was $15.0 \%$ (161 patients), with a mortality of $2.5 \%$ (four patients). RNA was subsequently attempted on 1172 patients between day 6 and day 16. Fifty two patients $(4.2 \%)$ were excluded because of technical inadequacies, and $46(3.7 \%)$ for administrative reasons. In all, 1074 patients were analysed. In all participating centres, the equilibrium RNA procedure was performed according to a standardised protocol. ${ }^{22}$ The unsmoothed studies were forwarded to the central laboratory for analysis, using a semiautomatic method. ${ }^{23}$ Left ventricular ejection fraction was calculated using standard techniques. ${ }^{23}$

\section{STATISTICAL ANALYSIS}

Quantitative data are expressed as mean (SD), with the exception of infarct size where, because of a severely rightward skewed distribution, the results are summarised as median (interquartile range). Kruskal-Wallis analysis of variance with time to treatment in four discrete intervals $(<2$ hours, $2-4$ hours, $\geqslant 4-6$ hours, $\geqslant 6$ hours) was used to assess the 
Table 2 Clinical characteristics of SPECT substudy patients

\begin{tabular}{|c|c|c|c|c|c|}
\hline & \multicolumn{4}{|c|}{ Time to thrombolysis } & \multirow[b]{2}{*}{$p$ Value } \\
\hline & $\begin{array}{l}<2 \text { hours } \\
(n=316)\end{array}$ & $2-4$ hours $(n=406)$ & $4-6$ hours $(n=217)$ & $>6$ hours $(n=160)$ & \\
\hline Age (years) & $57(11)$ & $59(12)$ & $59(12)$ & $58(11)$ & 0.036 \\
\hline Male sex & $84 \%$ & $79 \%$ & $74 \%$ & $75 \%$ & 0.029 \\
\hline \multicolumn{6}{|l|}{ History } \\
\hline Angina & $31 \%$ & $37 \%$ & $30 \%$ & $40 \%$ & 0.077 \\
\hline MI & $18 \%$ & $15 \%$ & $11 \%$ & $16 \%$ & 0.13 \\
\hline PTCA or CABG & $9 \%$ & $6 \%$ & $7 \%$ & $8 \%$ & 0.48 \\
\hline Hypertension & $37 \%$ & $42 \%$ & $42 \%$ & $50 \%$ & 0.05 \\
\hline Diabetes & $14 \%$ & $17 \%$ & $12 \%$ & $19 \%$ & 0.21 \\
\hline Never smoked & $28 \%$ & $29 \%$ & $34 \%$ & $35 \%$ & 0.015 \\
\hline Anterior infarct & $40 \%$ & $41 \%$ & $37 \%$ & $44 \%$ & 0.59 \\
\hline \multicolumn{6}{|l|}{ Type of thrombolysis } \\
\hline $\mathrm{t}-\mathrm{PA}$ & $40 \%$ & $29 \%$ & $18 \%$ & $17 \%$ & $<0.001$ \\
\hline Streptokinase & $60 \%$ & $71 \%$ & $82 \%$ & $83 \%$ & \\
\hline Other & $0 \%$ & $0 \%$ & $0 \%$ & $1 \%$ & \\
\hline $\begin{array}{c}\beta \text { Blockers before } \\
\text { randomisation }\end{array}$ & $19 \%$ & $24 \%$ & $22 \%$ & $26 \%$ & 0.32 \\
\hline \multicolumn{6}{|l|}{ At presentation: } \\
\hline Heart rate (beats/min) & $73(17)$ & $78(16)$ & $77(16)$ & $81(21)$ & 0.17 \\
\hline Diastolic BP (mm Hg) & $82(16)$ & $82(15)$ & $81(15)$ & $83(16)$ & 0.40 \\
\hline Systolic BP (mm Hg) & $132(24)$ & $133(24)$ & $131(22)$ & $134(24)$ & 0.58 \\
\hline $\mathrm{HR} \times$ diastolic $\mathrm{BP}$ & $6047(2160)$ & $6414(2001)$ & $6256(1936)$ & $6843(2643)$ & 0.002 \\
\hline $\mathrm{HR} \times$ systolic BP & $9701(3478)$ & 10448 (3173) & $10196(3105)$ & $10965(4060)$ & $<0.001$ \\
\hline
\end{tabular}

Data are expressed as mean (SD) or as percentage of patients.

significance of the univariate correlation between time to treatment and infarct size or ejection fraction. Univariate and multivariate analyses were used to adjust for independent predictors of infarct size and ejection fraction. An odds ratio was performed by comparing the rates of events and mortality at different time intervals. Age, sex, thrombolytic agent, myocardial infarction location, previous myocardial infarction, diabetes mellitus, congestive heart failure, and coronary artery bypass grafting were included as cofactors in the analysis to allow adjustment for these variables. Furthermore, a product term in the models of infarct size and left ventricular ejection fraction allowed for a time $\times$ thrombolysis type (tissue plasminogen activator (t-PA) $v$ others) interaction. These models also included adjustment for previous myocardial infarction, infarct location, and poloxamer 188 treatment.

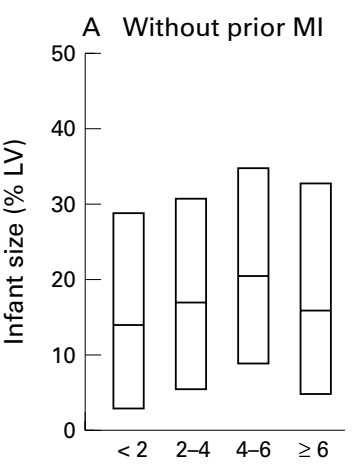

(n) (257) (344) (194) (134)

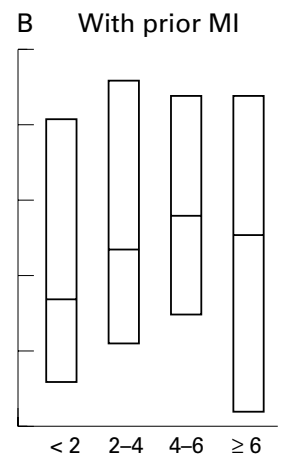

(57) (62) (23) (26)

Time to thrombolysis (hours)

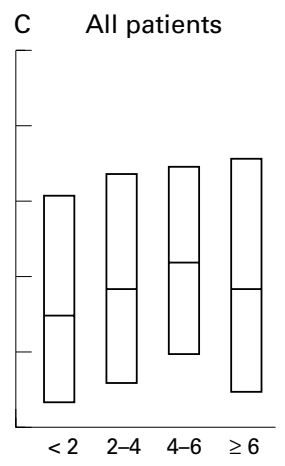

(316) (406) (217) (160) $\mathrm{p}=0.033$ (among all groups)

$\mathrm{p}=0.012$ ( $<2 \mathrm{hr}$ from other groups)

$\mathrm{p}=\mathrm{NS}$ (among 2-4, 4-6, $\geq 6$ hour groups)

$\mathrm{p}=\mathrm{NS}$ (interaction with prior $\mathrm{MI}$ )

Figure 1 Box plot of infarct size versus time to thrombolytic treatment, for each time interval. (A) Patients without previous myocardial infarction. (B) Patients with previous myocardial infarction. (C) All patients. Infarct size was significantly associated with elapsed time. Infarct size in the $<2$ hours subgroup was lower than in the other subgroups, among which there was no significant difference.

\section{Results}

OVERALL CLINICAL CHARACTERISTICS

Table 1 summarises the characteristics of the SPECT substudy compared with those of the non-SPECT CORE group. The mean (SD) time from symptom onset to reperfusion treatment for the SPECT group was 217 (159) minutes (range 5-1770), and for the nonSPECT group, 220 (146) minutes (range 10-1560). There were significant differences in some clinical characteristics between the two groups. The RNA substudy group had similar characteristics to the SPECT group. Table 2 summarises the characteristics of the infarct size group by time interval to thrombolysis. There were multiple significant differences between the four groups. Similar findings were noted in the RNA group.

\section{INFARCT SIZE VERSUS TIME TO REPERFUSION} TREATMENT

In the infarct size substudy, distribution of the 1099 patients was skewed toward early treatment, with two thirds of patients receiving thrombolysis within four hours of symptom onset. Infarct size was associated with time to reperfusion treatment ( $p=0.033$, fig 1$)$. However, infarct size was highly variable for any given time to thrombolysis, with a significant degree of overlap between different time intervals. The greatest effect of time to treatment was observed in the patients treated in $<2$ hours; infarct size in this subgroup (median $15 \%)$ was significantly $(p=0.012)$ lower than in the other subgroups (median 19\%). There was no significant difference among the other time subgroups.

The effect of time to thrombolysis on infarct size was consistent for patients without and with previous myocardial infarction (fig $1 \mathrm{~A}$ and 1B). The test of the interaction between time and previous myocardial infarction was not significant $(p=0.90)$, neither was the interaction between time to thrombolysis and thrombolytic type $(\mathrm{p}=0.20)$. 
Table 3 Adjusted effect of early thrombolysis

\begin{tabular}{|c|c|c|c|c|}
\hline \multirow[b]{2}{*}{ Factor } & \multicolumn{2}{|l|}{ Mean infarct size } & \multicolumn{2}{|c|}{ Mean ejection fraction } \\
\hline & Effect of variable & p Value & Effect of variable* & p Value \\
\hline \multicolumn{5}{|l|}{ Unadjusted $\dagger$} \\
\hline$\geqslant 2 \mathrm{~h}$ to thrombolysis & $3.1(1.3)$ & 0.018 & $-3.2(0.9)$ & 0.0004 \\
\hline \multicolumn{5}{|l|}{ Adjusted $\dagger$} \\
\hline$\geqslant 2 \mathrm{~h}$ to thrombolysis & $2.9(1.2)$ & 0.018 & $-3.1(0.8)$ & 0.0002 \\
\hline Previous MI & $8.3(1.5)$ & $<0.0001$ & $-5.8(1.0)$ & $<0.0001$ \\
\hline Anterior MI & $16.7(1.1)$ & $<0.0001$ & $-11.1(0.8)$ & $<0.0001$ \\
\hline $\mathrm{t}-\mathrm{PA}$ & $-3.5(1.3)$ & 0.005 & $0.9(0.8)$ & 0.33 \\
\hline Poloxamer 188 & $-1.6(1.2)$ & 0.18 & $-1.4(0.8)$ & 0.079 \\
\hline
\end{tabular}

${ }^{\star}$ Data refer to absolute changes in percentage (mean (SEM)); †changes relative to patients treated for less than two hours.

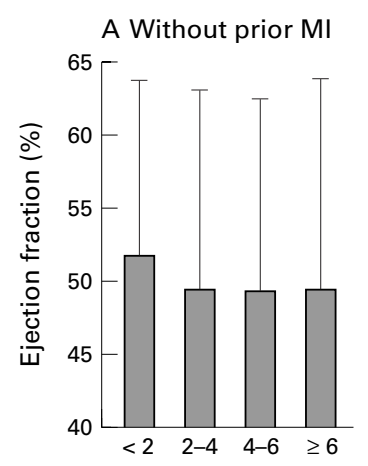

(n) (253) (339) (187) (118)

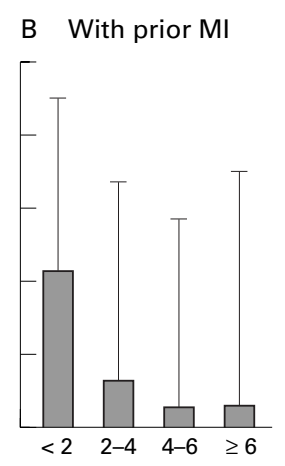

(57) (72) (27) (21)

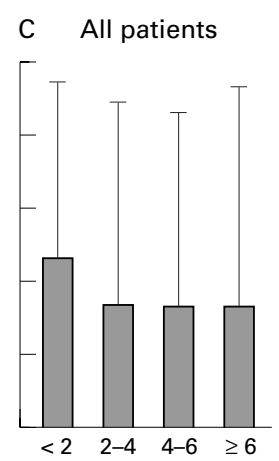

(310) (411) (214) (137)
Time to thrombolysis (hours)

$$
\begin{aligned}
& p=0.0006 \text { (among all groups) } \\
& p=0.001(<2 \text { hour from other groups) } \\
& p=0.97 \text { (among } 2-4,4-6, \geq 6 \text { hour groups) } \\
& p=0.08 \text { (interaction with prior } \mathrm{MI})
\end{aligned}
$$

Figure 2 Bar graph of ejection fraction versus time to thrombolysis, for each time interval. (A) Patients without previous myocardial infarction. (B) Patients with previous myocardial infarction. (C) All patients. Ejection fraction was associated with time, $p=0.006$. Ejection fraction in the $<2$ hours subgroup was higher than in the other subgroups, among which there was no significant difference.

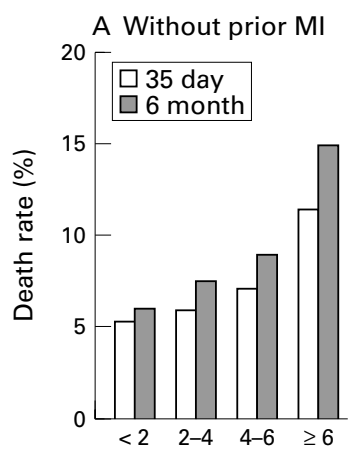

35 day (n) (568) (897) (438) (360) 6 month (n) (551) (866) (427) (349)

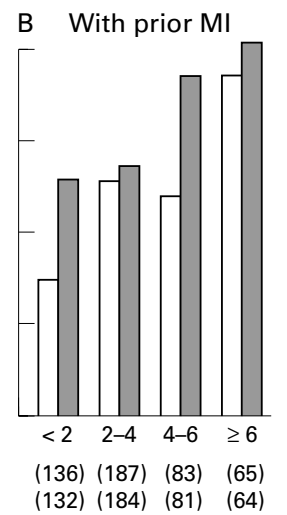

Time to thrombolysis (hours)

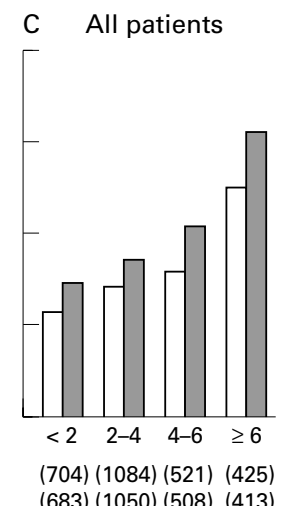

(683) (1050) (508) (413)

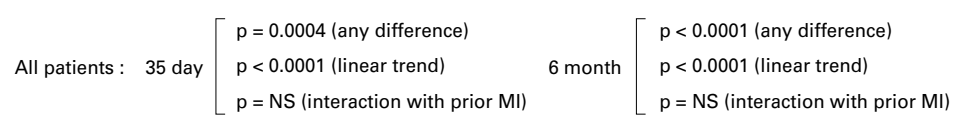

Figure 3 Bar graph of the 35 day and six month cumulative mortality for the CORE thrombolysis population, for each time interval. (A) Patients without previous myocardial infarction. (B) Patients with previous myocardial infarction. (C) All patients. The significant association between the cumulative 35 day and six month mortality and time to thrombolysis is shown.
The mean difference in infarct size between those receiving early $(<2$ hours) compared with more delayed treatment ( $\geqslant 2$ hours) was adjusted for confounding variables (table 3 ). The unadjusted mean increase in infarct size associated with later thrombolysis was $3.1 \%$ $(\mathrm{p}=0.018)$, and this remained unchanged after adjustment $(2.9 \% ; \mathrm{p}=0.018)$. On average, anterior myocardial infarction was associated with a mean increase in infarct size of $16.7 \%$ ( $p<0.0001)$. Previous myocardial infarction increased mean infarct size by $8.3 \%$ $(\mathrm{p}<0.0001)$.

EJECTION FRACTION VERSUS TIME TO REPERFUSION TREATMENT

For the 1074 patients in the RNA substudy, the distribution was skewed toward early treatment, with two thirds receiving thrombolysis within four hours of symptom onset. Ejection fraction was associated with time to reperfusion treatment $(p=0.006$, fig 2). Ejection fraction was also highly variable for any given time to thrombolysis. The greatest benefit of time on ejection fraction was again observed in the $<2$ hour subgroup. There were no significant differences in mean ejection fraction among the other subgroups.

The benefit of time to thrombolysis on ejection fraction remained consistent for patients without and with previous myocardial infarction (fig $2 \mathrm{~A}$ and $2 \mathrm{~B}$ ). The interaction of time to thrombolysis and previous myocardial infarction was of borderline significance $(p=0.076)$, but this effect was paradoxical in that time appeared to have less impact on the group without previous myocardial infarction. Furthermore, the interaction between time to thrombolysis and thrombolysis type was nonsignificant $(p=0.32)$.

The observed mean difference in ejection fraction between the early thrombolysis group ( $<2$ hours) and the more delayed ( $\geqslant 2$ hours) groups was $3.2 \%$. Adjustment for confounding variables had little effect (table 3). Previous myocardial infarction and anterior infarct location both strongly predicted reduced mean ejection fraction ( $p<0.0001$ for each).

\section{CLINICAL OUTCOMES AND TIME TO}

THROMBOLYSIS

There were 2770 patients in whom time to thrombolysis was known. Of these, 2734 $(98.7 \%)$ were followed to day 35 and 2656 (95.9\%) to six months. There were 211 deaths in the group of 2734 patients at 35 days. Figure 3 depicts the strong association between time to thrombolysis and the 35 day and six month mortality. At 35 days and at six months, regardless of previous myocardial infarction, mortality of the $<2$ hours subgroup was less than half that for the $\geqslant 6$ hours subgroup $(\mathrm{p}<0.0001)$. The $2-4$ hours and $\geqslant 4-6$ hours subgroups also had a lower mortality $(p<0.03)$ than the $\geqslant 6$ hours subgroup ( $\mathrm{p}<0.0001$ for linear trend).

Adjustment for the listed variables (table 4) had little effect on the odds ratio for each interval of time to thrombolysis but did affect the $p$ value (0.0004 unadjusted to 0.038 adjusted). 
Table 4 Thirty five day death rate, adjusted analysis

\begin{tabular}{llllll}
\hline \multicolumn{5}{c}{ Odds ratio by time to thrombolysis } \\
\cline { 2 - 5 } & $\begin{array}{l}\text { < hours } \\
(n=704)\end{array}$ & $\begin{array}{l}2-4 \text { hours } \\
(n=1084)\end{array}$ & $\begin{array}{l}\geqslant 4-6 \text { hours } \\
(n=521)\end{array}$ & $\begin{array}{l}>6 \text { hours } \\
(n=425)\end{array}$ & $p$ Value \\
\hline Unadjusted & 1.0 & 1.27 & 1.42 & 2.37 & 0.0004 \\
Adjusted & 1.0 & 1.15 & 1.10 & 1.81 & 0.038
\end{tabular}

^Adjusted for age, sex, thrombolytic agent, infarct location, poloxamer 188 regimen, and history of previous myocardial infarction, diabetes mellitus, congestive heart failure, and coronary artery bypass grafting.

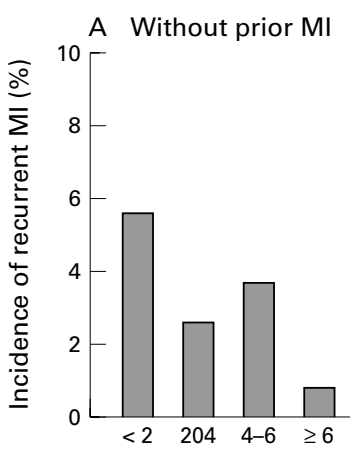

(n) $(568)(897)(438)(360)$

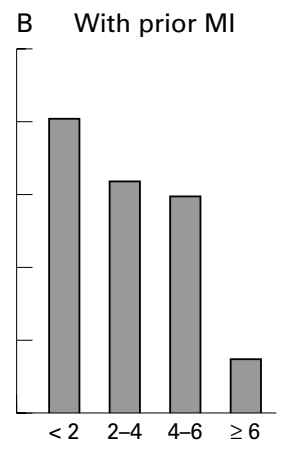

(136) (187) (83) (65)

Time to thrombolysis (hours)

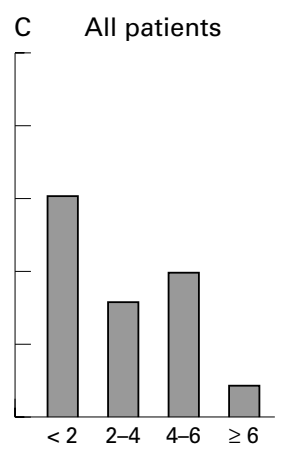

(704) (1084) (521) (425) $\mathrm{p}=0.0001$ (any difference)

$\mathrm{p}<0.0001$ (linear trend)

$\mathrm{p}=\mathrm{NS}$ (interaction with prior MI)

Figure 4 Bar graph illustrating the 35 day incidence of recurrent myocardial infarction, for each time interval. (A) Patients without previous myocardial infarction. (B) Patients with previous myocardial infarction. (C) All patients. There was a significant inverse trend between reinfarction rate and time to thrombolysis. The highest reinfarction rate $(<2$ hours subgroup) was six times higher than that of the $\geqslant 6$ hours subgroup. The subgroups treated at 2-4 hours and $\geqslant 4-6$ hours had an intermediate level of reinfarction.

For the 35 day combined incidence of recurrent myocardial infarction, shock, and death, subgrouped by time to thrombolysis, there is a trend of increasing combined event rates with elapsed time of $\geqslant 2$ hours, regardless of previous myocardial infarction. However, the $<2$ hours group paradoxically had a higher combined event rate than the $2-4$ hours and $\geqslant 4-6$ hours groups, regardless of previous myocardial infarction. After adjustment, the odds ratio for each interval of time to thrombolysis remained similar $(\mathrm{p}=0.19)$ to the unadjusted ratio.

The difference in time trends in the 35 day mortality and the 35 day combined event outcome is explained by the 35 day incidence of recurrent myocardial infarction (fig 4). There was a significant inverse trend between recurrent myocardial infarction and time to thrombolysis $(p<0.0001)$, regardless of previous myocardial infarction. In all patients, the highest reinfarction rate $(<2$ hours subgroup $=6.1 \%)$ was six times higher than that of the $\geqslant 6$ hours subgroup $(0.9 \%, p<0.0001)$.

\section{Discussion}

IMPORTANCE OF EARLY REPERFUSION

This study confirms the beneficial effects of earlier reperfusion treatment in acute myocardial infarction. However, the magnitude of this time benefit on infarct size and ejection fraction was considerably less than the impact of other known determinants of outcome. A time to treatment of more than two hours was associated with an increase in infarct size of less than $40 \%$ of the increase associated with either a history of previous myocardial infarction or anterior infarct location, the most important determinant of infarct size in this model. These data support earlier animal ${ }^{34-26}$ and clinical studies, ${ }^{10} 1527$ in which an important determinant of infarct size was myocardium at risk. The amount of myocardium at risk has been shown by SPECT sestamibi to be twofold greater for anterior than for nonanterior infarcts. ${ }^{28}$ The smaller effect of time on infarct size and ejection fraction is also consistent with the GUSTO (global utilization of streptokinase and t-PA for occluded coronary arteries) 30 day mortality data. ${ }^{29}$ Of the 12 independent predictors of mortality in that study, time provided only $1 \%$ of the prognostic information, while previous myocardial infarction provided $2.8 \%$ and anterior infarct location $6 \%$.

These data reinforce the striking survival benefit of very early thrombolysis and the concept of the "golden hour." 8 The greatest mortality benefit in this study was achieved when thrombolysis was given within two hours of symptom onset. Beyond that time, mortality reduction was attenuated. An explanation for the early survival benefit is time dependent myocardial salvage, ${ }^{9}$ postulated to operate when thrombolysis occurs within one to two hours of symptom onset. The infarct size substudy, with its greatest effect of time at less than two hours, appears to support this concept.

Although results of the GUSTO trial ${ }^{30} 31$ show mortality rates in favour of accelerated tPA over streptokinase, in the present study the test of the interaction between time to thrombolysis and thrombolysis type was not significant, which further highlights the importance of early reperfusion treatment.

MECHANISM OF BENEFIT OF LATER TREATMENT The mechanism of the survival benefit with later thrombolysis has been controversial. ${ }^{1457811}$ In this study and other trials, ${ }^{1132-34}$ the mortality benefit of time beyond the two hour threshold exceeded its impact on left ventricular function and infarct size. These discrepancies suggest survival mechanisms independent of the preservation of left ventricular function and myocardial salvage, which may include prevention of cardiac rupture and electrical instability, and prevention or limitation of infarct expansion and left ventricular remodelling. ${ }^{18}$ Perfusion of the infarct related artery is also more closely related to outcome than left ventricular function. ${ }^{35}$ This open artery may provide mortality benefits by supplying collateral flow when other areas of the myocardium later become jeopardised.

Another potential explanation for the discrepancy in the effect of time on survival and ejection fraction is the time to treatment paradox. Survival of some patients with severe left ventricular dysfunction who otherwise may have died can presumably mask the gain in ejection fraction in reperfused patients and 
result in a discrepancy between the survival benefit and preservation of left ventricular function. ${ }^{36}$

LINEAR AND NON-LINEAR EFFECTS OF TIME

Although a monotonic but non-linear relation between the duration of coronary occlusion and final infarct size has been shown in animal models of reperfusion, ${ }^{2}{ }^{3}$ results of previous clinical trials using mortality support both a linear ${ }^{15}$ and a non-linear ${ }^{6-829}$ relation. This study shows a linear effect on mortality but a non-linear effect on infarct size. The latter is consistent with a previous single centre study. ${ }^{9}$

Concordant with the infarct size data and previous smaller studies, ${ }^{11-13} 18$ our ejection fraction data found a significant non-linear effect of time to thrombolysis, confirming that earlier initiation of thrombolysis preserves left ventricular function better.

On the other hand, the benefits of time on both 35 day and six month mortality suggest a linear association. While the linear versus nonlinear controversy remains unresolved, this investigation shows the importance of very early thrombolysis, where mortality of the earliest treatment group was less than half that of the most delayed treatment group.

\section{RECURRENT INFARCTION}

In agreement with previous data, ${ }^{37}$ the reinfarction rate in this study was highest in the earliest treatment group, which was sixfold higher than that of the most delayed group. A possible explanation is that greater myocardial salvage renders more viable myocardium vulnerable to subsequent ischaemia and infarction. ${ }^{18}$ Obviously, improved survival with earlier thrombolysis results in more patients available for recurrent ischaemia and reinfarction.

\section{STUDY LIMITATIONS}

A potential sampling bias was introduced by the exclusion of nearly $40 \%$ of eligible patients without follow up imaging studies. A few centres enrolled patients before SPECT validation. Patients may have died before follow up was complete, or they may have refused or been too ill for the scheduled follow up. The latter supposition is supported by the higher event rate in eligible patients without follow up SPECT. However, reanalysis with only patients alive at 16 days yielded comparable event rates, suggesting early mortality as the major explanation for failure to obtain a follow up SPECT.

Given the substantial differences in baseline characteristics of patients presenting at different times, we cannot rule out the presence of other important yet unidentified baseline differences that may account for the higher mortality of the later treatment groups. As shown in table 4, adjustment for known baseline differences decreases the apparent significance of time $(p=0.0004$ to $p=0.038)$. This modest significance might conceivably be lost with additional adjustment (as might occur with true randomisation). However, in previous larger studies, ${ }^{29}$ the significance of time was considerably greater, suggesting that the modest effect observed here may be a reflection of the limited number of deaths $(n=211)$.

Time to thrombolysis does not necessarily represent time to reperfusion, which is likely to be a more important predictor of outcome. However, O'Keefe and colleagues previously showed that direct percutaneous transluminal coronary angioplasty beyond two hours after symptom onset had a more variable but lesser impact on myocardial salvage than did earlier restoration of angiographic flow. ${ }^{38}$

Finally, myocardium at risk and collateral/ residual flow, both important determinants of final infarct size in multiple animal and clinical studies, ${ }^{2101524-27}$ were not assessed in this study.

\section{IMPLICATIONS}

Although the benefits of time to thrombolysis are smaller than those of other determinants of outcome in acute myocardial infarction, for a given thrombolytic agent, time to thrombolysis is the only variable amenable to intervention. These findings emphasise the need to minimise the time delay to reperfusion treatment and to initiate thrombolysis within two hours of symptom onset.

This study was supported by a grant from Burroughs Wellcome Co, USA.

1 Fibrinolytic Therapy Trialists' (FTT) Collaborative Group. Indications for fibrinolytic therapy in suspected acute myocardial infarction: collaborative overview of early mortality and major morbidity results from all randomised trials of more than 1000 patients. Lancet 1994;343:311-22.

2 Reimer KA, Jennings RB. The "wavefront phenomenon" of myocardial ischemic cell death, II: transmural progression of necrosis within the framework of ischemic bed size (myocardium at risk) and collateral flow. Lab Invest 1979;40:633-44

3 Reimer KA, Heide RSV, Richard VJ. Reperfusion in acute myocardial infarction: effect of timing and modulating factors in experimental animal models. Am 7 Cardiol 1993;72. 13-21G.

4 Kennedy JW, Martin GV, Davis KB, et al. The Western Washington Intravenous Streptokinase in Acute Myocardial Infarction Randomised Trial. Circulation 1988;77:34552 .

5 Raitt MH, Maynard C, Wagner G, et al. Relation between symptom duration before thrombolytic therapy and final myocardial infarct size. Circulation 1996;93:48-53.

6 Gruppo Italiano per lo Studio della Sopravvivenza nell'Infarto Miocardico. GISSI-2: a factorial randomised trial of alteplase vs streptokinase and heparin vs no heparin among 12,490 patients with acute myocardial infarction. Lancet 1990;336:65-71.

7 Newby LK, Rutsch WR, Califf RM, et al. for the GUSTO-I Investigators. Time from symptom onset to treatment and outcomes after thrombolytic therapy. F Am Coll Cardiol 1996;27:1646-55.

8 Boersma E, Maas AC, Deckers JW, et al. Early thrombolytic treatment in acute myocardial infarction: reappraisal of the golden hour. Lancet 1996;348:771-5.

9 Milavetz JJ, Giebel DW, Christian TF, et al. Time to therapy and salvage in myocardial infarction. $₹ \mathrm{Am}$ Coll Cardiol and salvage in my

10 Christian TF, Schwartz RS, Gibbons RJ. Determinants of infarct size in reperfusion therapy for acute myocardial infarction. Circulation 1992;86:81-90.

11 Ritchie JL, Cerqueira M, Maynard C, et al. Ventricular function and infarct size: the Western Washington intravenous streptokinase in myocardial infarction trial. $\mathcal{F} \mathrm{Am}$ Coll Cardiol 1988;11:689-97.

12 Weaver WD, Cerqueira M, Hallstrom AP, et al, for the Myocardial Infarction Triage and Intervention Project Group. Prehospital-initiated vs hospital-initiated thrombolytic therapy: the myocardial infarction triage and intervention trial. $\mathscr{F} A M A$ 1993;270:1211-16.

13 Linderer T, Schröder R, Arntz R, et al. Prehospital thrombolysis: beneficial effects of very early treatment on infarct size and left ventricular function. $\mathcal{F} \mathrm{Am}$ Coll Cardiol 1993;22:1304-10.

14 Collaborative Organization for RheothRx Evaluation (CORE). Effects of RheothRx on mortality, morbidity, left ventricular function, and infarct size in patients with acute myocardial infarction. Circulation 1997;96:192-201. 
15 Gibbons RJ, Verani MS, Behrenbeck T, et al. Feasibility of tomographic Tc-99m-hexakis-2-methoxy-2-methylpropylisonitrile imaging for the assessment of myocardial area at risk and the effect of acute treatment in myocardial infarction. Circulation $1989,80: 1277-86$

16 O'Connor MK, Hammell TC, Gibbons RJ. In vitro validation of a simple tomographic technique for estimation of percent myocardium "at risk" following adminstration of Tc-99m isonitrile. Eur f Nucl Med 1990;17:69-76.

17 LATE Study Group. Late assessment of thrombolytic efficacy (LATE) study with alteplase 6-24 hours after onset of acute myocardial infarction. Lancet 1993;342:759-66.

18 Gersh BJ, Anderson JL. Thrombolysis and myocardial salvage: results of clinical trials and the animal paradigmparadox or predictable? Circulation 1993;88:296-305.

19 Verani MS, Jeroudi MO, Mahmarian JJ, et al. Quantification of myocardial infarction during coronary occlusion and myocardial salvage after reperfusion using cardiac imaging mith technetium- $99 \mathrm{~m}$ hexakis 2 -methoxyisobutyl isonitrile. f Am Coll Cardiol 1988;12:1573-81.

20 Christian TF, Behrenbeck T, Pellika PA, et al. Mismatch of left ventricular function and infarct size demonstrated by technetium-99m isonitrile imaging after reperfusion therapy for acute myocardial infarction: identification of myocardial stunning and hyperkinesia. $\mathcal{F}$ Am Coll Cardiol 1990;16:1632-8.

21 Udelson JE, Coleman PS, Metherall J. Predicting recovery of severe regional dysfunction: comparison of resting scintigraphy with 201-Tl and 99m-Tc sestamibi. Circulation 1994;89:2552-61.

22 Callahan RJ, Froelich JW, McKusick KA, et al. A modified method for the in vivo labeling of red blood cells with Tc-99m: concise communication. F Nucl Med 1982;23. 315-18.

23 Burns RJ, Druck MN, Woodward DS, et al. Repeatability of estimates of left-ventricular volume from blood pool counts. F Nucl Med 1983;24:775-81.

24 Lowe JE, Reimer KA, Jennings RB. Experimental infarct size as a function of the amount of myocardium at risk. Am size as a function of the amol 1978;90:363-79.
f Pathol

25 Judgett BI, Hutchins GM, Bulkley BH, et al. Myocardial infarction in the conscious dog: three-dimensional mapping of infarct, collatel flow and region at risk. Circulation 1979;60:1141-50

26 Reimer KA, Ideker RE, Jennnings RB. Effect of coronary occlusion site on ischemic bed size and collateral blood flow in dogs. Cardiovasc Res 1981;15:668-74.
27 Feiring AJ, Johnson MR, Kioschos JM, et al. The importance of the determination of the myocardial area at risk in the evaluation of the outcome of acute my
infarction in patients. Circulation 1987;75:980-7.

28 Christian TF, Gibbons RJ, Gersh BJ. Effect of infarct location on myocardial salvage assessed by technetium- $99 \mathrm{~m}$ isonitrile. $\mathcal{F}$ Am Coll Cardiol 1991;17:1303-8.

29 Lee KL, Woodlief LH, Topol EJ, et al, for the GUSTO-I Investigators. Predictors of 30-day mortality in the era of reperfusion for acute myocardial infarction: results from an international trial of 41,021 patients. Circulation 1995:91: 1659-68.

30 The GUSTO investigators. An international randomized trial comparing four thrombolytic srategies for acute myocardial infarction. N Engl f Med 1993;329:673-82.

31 Califf RM, White HD, Van de Werf F, et al. One-year results from the Global Utilization of Streptokinase and TPA for Occluded Coronary Arteries (GUSTO-I) trial. Circulation 1996;94:1233-8.

32 Kennedy JW, Ritchie JL, Davis KB, et al. Western Washington randomized trial of intracoronary streptokinase in acute myocardial infarction. N Engl f Med 1983;309:147782.

33 Sheehan FH, Braunwald E, Canner P, et al. The effect of intravenous thrombolytic therapy on left ventricular function: a report on tissue-type plasminogen activator and streptokinase from the Thrombolysis in Myocardial Infarction (TIMI Phase I) trial. Circulation 1987;75:817-29.

34 Dalen JE, Gore JM, Braunwald E, et al, and the TIMI Investigators. Six- and twelve-month follow-up of the phase I thrombolysis in myocardial infarction (TIMI) trial. $\mathrm{Am} \mathfrak{F}$ Cardiol 1988;62:179-85.

35 Stadius ML, Davis K, Maynard C, et al. Risk stratification for a year survival based on characteristics identified in the early hours of acute myocardial infarction. Circulation 1986;74:703-11.

36 Van de Werf F. Discrepancies between the effects of coronary reperfusion on survival and left ventricular function. Lancet 1989;i:1367-8.

37 Timm TC, Ross R, McKendall GR, et al. Left ventricular function and early cardiac events as a function of time to treatment with t-PA: a report from TIMI II [abstract]. Circulation 1991;84(suppl 2):II-230.

38 O'Keefe JH, Grines CL, DeWood MA, et al. Factors influencing myocardial salvage with primary angioplasty. $\mathcal{F}$ Nucl Cardiol 1995;2:35-41. 